\title{
Comparison of Outcomes in Conservative versus Surgical Treatments for Ludwig's Angina
}

\author{
Benlance Ekaniyere Edetanlen Birch Dauda Saheeb \\ Department of Oral and Maxillofacial Surgery, School of Dentistry, University of Benin, Benin City, Nigeria
}

\section{Significance of the Study}

- Ludwig's angina is usually fatal if not managed successfully in the early stage in resource-challenged centers. Controversies abound concerning early surgical intervention in individuals presenting early with this life-threatening condition. Therefore, this study sought to determine the outcome of surgical intervention in early stages of this condition in a resource-challenged center.

\section{Keywords}

Ludwig's angina · Conservative · Surgical · Treatment · Airway compromise

\section{Abstract}

Objective: To compare the treatment outcomes in patients with early stage Ludwig's angina who received intravenous antibiotics alone with those who received surgical decompression and intravenous antibiotics. Subjects and Methods: Individuals with early stage Ludwig's angina were studied using a retrospective cohort study design from August 1997 to September 2017. Data were collected from case notes and logbooks. Appropriate statistical tests were chosen to analyze both the independent and outcome variables. Using 2-tailed test, a level of significance of 0.05 was chosen. Results: A total of 55 patients comprising 38 (69.1\%) males and 17 (30.9\%) females were studied. The conservative group had a higher number of cases that developed airway compromise (26.3\%) when compared to those with surgical approach (2.9\%). There was an association between the treatment approach and the development of airway com-

\begin{tabular}{ll}
\hline KARGER & $\begin{array}{l}\text { ( ) 2018 The Author(s) } \\
\text { Published by S. Karger AG, Basel }\end{array}$ \\
E-Mail karger@karger.com & $\begin{array}{l}\text { This is an Open Access article licensed under the Creative Commons } \\
\text { Attribution-NonCommercial-4.0 International License (CC BY-NC) } \\
\text { (http://www.karger.com/Services/OpenAccessLicense), applicable to } \\
\text { the online version of the article only. Usage and distribution for } \\
\text { commercial purposes requires written permission. }\end{array}$
\end{tabular}

promise $\left(x^{2}[1]=4.83, p=0.03\right)$. Conclusion: There was a higher incidence of airway compromise in patients treated with intravenous antibiotics alone than in those treated with surgical decompression and intravenous antibiotics.

(c) 2018 The Author(s)

Published by S. Karger AG, Basel

\section{Introduction}

Ludwig's angina is described as a potentially lethal, rapidly spreading cellulitis, involving the sublingual and submandibular spaces, manifested by a brawny suprahyoid induration, tender swelling in the floor of the mouth, and elevation and posterior displacement of the tongue [1]. Certain peculiarities of cellulitis involving the submandibular and sublingual spaces are their closeness to the pharyngeal and laryngeal airways, the rate of spread of infection from sublingual space to the epiglottis causing laryngeal airway obstruction, limitation of infection, and edema by deep cervical fascia, mandible and the hyoid causing the tongue and floor of the mouth to elevate

Benlance Ekaniyere Edetanlen

Department of Oral and Maxillofacial Surgery

College of Medical Sciences, University of Benin

Mail code 30001, P.M.B.1154, 87 New Lagos Road, Ugbowo, Benin-City (Nigeria)

E-Mail ehiben2002@yahoo.com 
and displace posterior to compromise the pharyngeal airway [2]. The majority of these causes are odontogenic in origin. The other known causes are peritonsillar or parapharyngeal abscess, mandibular fracture, oral laceration or piercing and submandibular sialadenitis. Predisposing factors are dental caries, recent dental treatment, and systemic illnesses such as diabetes mellitus, malnutrition, and alcoholism, compromised immune system such as AIDS and organ transplantation and trauma [3].

Recent reports encourage the conservative management of the airways over the conventional surgical airway management [4-6]. However, despite the recent trend in airway control, several clinicians [7-10] still encourage watchful waiting in the treatment of Ludwig's angina while others $[11,12]$ encourage early surgical drainage to decompress the spaces involved in the cellulitis to either relieve or prevent airway compromise. Early surgical drainage also serves other purposes such as enhancing antibiotic penetration, allowing prompt drainage should suppuration develop, providing samples for gram staining, culture and sensitivity and allowing the placement of a drain to drain pus collection [13]. Currently, it appears that there is no consensus with regard to the management of either early or late stage of Ludwig's angina. Several case reports $[6,14]$ and retrospective studies $[2,15]$ have documented that early intervention is the mainstay of treatment and that most etiological factors are odontogenic in origin. Many reports tend to overlook the management of the early stage of this condition in resourcechallenged centers in developing countries.

Although several studies have reported successful outcomes following the use of intravenous antibiotics and surgical decompression $[8,9]$ with or without airway management, several others have also reported the same following the use of intravenous antibiotics alone [6,7]. However, investigations of the outcome of various treatment options in the early stage of this disease have not been well documented in the literature. Therefore, the purpose of this study was to compare the treatment outcomes of Ludwig's angina patients who present in their early stages and who received intravenous antibiotics alone with those who received surgical decompression and intravenous antibiotics.

\section{Subjects and Methods}

This was a retrospective cohort study conducted from August 1997 to September 2017. The study sample was derived from a population of patients who presented with classical early stage of Ludwig's angina. Larawin et al. [16] documented that the early stage of Ludwig's angina is when the airway is not compromised, while the late stage is when features of airway obstruction are actually present.

Patients were excluded from the study if they presented with late stage of Ludwig's angina, if their case notes contained insufficient information, comorbidity or if patients had any previous airway management. We ensured that both groups had the same type of antibiotics for the same duration and that there were no concomitant infections for the same exclusion criteria that were used for the 2 groups. The airways were assessed on presentation based on clinical examination and pulse oximetry. A patient was said to have respiratory compromise in the presence of anxiety, cyanosis, stridor, greater than 25 respiratory rate, less than $95 \%$ $\mathrm{O} 2$ saturation, inability to lie in the supine position, alar flaring, supraclavicular and intercostal in-drawing during inspiration [16]. All patients were started on empirical intravenous cefotaxime $1 \mathrm{gm}$ twice daily and intravenous metronidazole $500 \mathrm{mg}$ thrice daily for 5 days, which was later modified based on culture and sensitivity tests. The surgical approach groups had surgical decompression via separate stab incisions on the submandibular space bilaterally and the submental space. Separate tube drains were placed and secured to the skin with silk sutures. All patients were monitored for any development of airway compromise, and emergency tracheostomy was performed in those who developed airway compromise.

Data were collected from case notes and log books of resident registrars, and they were cross-checked with records from the emergency department information system. The predictor variables were type of treatments (intravenous antibiotic therapy alone or conservative approach groups, and surgical intervention and intravenous antibiotics therapy or surgical approach groups) while airway compromise was measured as the dependent variable. The covariates measured were age and sex of the patients, length of hospital stay (LOS), complications, and mortality. In univariate analysis, continuous data were summarized in ranges, means, and standard deviations while proportions and percentages were summarized for categorical variables. In the bivariate analysis, comparisons between continuous variable of the groups were done using the independent 2 sample $t$ test while that of the categorical variables were done using the Mann-Whitney test. In univariable and multivariable analyses, assessment of associations between the independent and dependent variables were done using the Fisher exact test and logistic regression, respectively. All data were entered in SPSS version 17 and the $p$ value was set at 0.05 .

\section{Results}

A total of 55 patients comprising 38 (69.1\%) males and 17 (30.9\%) females were studied. The mean age of the surgical approach groups was 38.6 years, with a minimum age of 32 years and a maximum age of 53 years. The age range and mean of the conservative approach group were 17-82 and 41.6 years, respectively. The surgical approach groups were slightly older than the conservative groups (Table 1), although the difference was not statistically sig- 
nificant. Of the 19 patients who had conservative treatment, 5 (26.4\%) developed airway compromise while only 2 of (5.56\%) 36 patients had airway compromise following surgical treatment. The mean LOS in the surgical approach group was 5.2 days while in the conservative groups LOS was 7.5 days; this difference was statistically significant $(p=0.03)$. No mortality and complications were recorded in both groups.

The groups that had conservative treatment were slightly older than those that had surgical treatment with an age difference of 3 years (95\% CI -5.46 to $11.3, t=$ 702 ), but this was not statistically significant as shown in Table 1. Though there were fewer individuals in the conservative group $(34.5 \%)$ than in the surgical group $(65.5 \%)$, a higher number of individuals in the conservative group developed airway compromise $(26.3 \%)$ when compared to those with the surgical approach (2.90\%). This observed difference was statistically significant, as shown in Table $1(\mathrm{U}=271, \mathrm{Z}=-2.18)$. There was an association between the treatment approach and the development of airway compromise $\left(\chi^{2}[1]=4.83, p=0.03\right)$.

A comparison of age and gender for patients in the surgical approach group who did and did not develop airway compromise is shown in Table 2. Younger patients were more likely to develop airway compromise than older patients, although this difference was not statistically significant $(p=0.58)$. Similarly, males were more likely to develop this complication than females but this too was not significant $(p=0.41)$. Table 3 presented a comparison of age and gender in the conservative approach groups who did and did not develop airway compromise. Older patients and female patients were more likely to develop airway compromise as compared to younger and male patients, but these differences were not significant ( $p=$ 0.55 for age and $p=0.36$ for gender, respectively).

In the age- and gender-adjusted multivariate analysis, Table 4 shows that there was a significant association between types of treatment administered and the development of airway compromise. While there was a slight but non-significant association between the age and the treatment administered, there was no association with the gender of the patients.

\section{Discussion}

The primary purpose of this study was to compare the treatment outcomes of early stage of Ludwig's angina using intravenous antibiotic therapy alone and surgical intervention with intravenous antibiotic therapy. Our hy-
Table 1. Comparison of conservative and surgical approach groups

\begin{tabular}{lccc}
\hline Variables & $\begin{array}{l}\text { Surgical } \\
\text { approach } \\
\text { groups }(n=36)\end{array}$ & $\begin{array}{l}\text { Conservative } \\
\text { approach } \\
\text { groups }(n=19)\end{array}$ & $p$ value \\
\hline $\begin{array}{l}\text { Age, years } \\
\quad \text { Range }\end{array}$ & $32-53$ & $17-82$ & \\
$\quad \begin{array}{l}\text { Mean } \pm \text { SD } \\
\text { Gender, } n(\%)\end{array}$ & $38.6 \pm 13.1$ & $41.6 \pm 17.5$ & 0.49 \\
$\quad \begin{array}{l}\text { Males } \\
\text { Females }\end{array}$ & $27(75.0)$ & $11(57.9)$ & \\
$\begin{array}{l}\text { Airway } \\
\text { compromise, } n(\%)\end{array}$ & $9(25.0)$ & $8(42.1)$ & 0.29 \\
$\quad \begin{array}{l}\text { Presence } \\
\text { Absence }\end{array}$ & $2(2.90)$ & $5(26.3)$ & \\
\hline
\end{tabular}

Table 2. Comparison of complications in the surgical approach groups

\begin{tabular}{lccc}
\hline Variables & Presence & Absence & $p$ value \\
\hline $\begin{array}{l}\text { Airway } \\
\quad \text { compromise, } n(\%)\end{array}$ & $2(5.60)$ & $34(94.4)$ & \\
$\begin{array}{l}\text { Age, years } \\
\quad \text { Range }\end{array}$ & $33-34$ & $18-64$ & \\
$\quad$ Mean \pm SD & $33.5 \pm 0.71$ & $38.9 \pm 13.5$ & 0.58 \\
Gender, $n(\%)$ & $2(5.60)$ & $9(25.0)$ & \\
$\quad$ Male & $0(0.00)$ & $25(69.4)$ & 0.41 \\
$\quad$ Female & & \\
\hline
\end{tabular}

Table 3. Comparison of complications in the conservative approach groups

\begin{tabular}{lccc}
\hline Variables & Presence & Absence & $p$ value \\
\hline $\begin{array}{l}\text { Airway } \\
\quad \text { compromise, } n(\%)\end{array}$ & $5(26.3)$ & $14(73.7)$ & \\
Age, years & & & \\
$\quad$ Range & $21-82$ & $17-69$ & \\
$\quad$ Mean \pm SD & $45.8 \pm 25.6$ & $40.1 \pm 14.6$ & 0.55 \\
Gender, $n(\%)$ & $2(10.5)$ & $8(42.1)$ & \\
$\quad$ Male & $3(15.8)$ & $6(31.6)$ & 0.36 \\
$\quad$ Female & & & \\
\hline
\end{tabular}

pothesis was that patients treated with intravenous antibiotics and surgical intervention will have a lower incidence of development of airway compromise when compared to intravenous antibiotic alone due to failure of antibiotic therapy that could occur with its use.

There were significant associations between treatment choice and the development of airway compromise in both univariable and multivariable analyses. 
Table 4. Association between treatment approach and development of late stage Ludwig's angina

\begin{tabular}{|c|c|c|c|c|c|c|c|}
\hline Treatment approaches & 1.92 & 0.93 & 4.25 & 1 & 0.04 & 6.82 & $1.10-42.3$ \\
\hline Gender & -0.72 & 1.04 & 0.49 & 1 & 0.48 & 0.48 & $0.06-3.68$ \\
\hline
\end{tabular}

Our data suggest that the use of surgical approach versus conservative approach seemed to influence the development of airway compromise in patients with early stage Ludwig's angina. The wide variability in the incidence of airway compromise relative to gender and age in both groups of patients as well as not finding any association between them is a clear indication that all categories of patients have the same chance of developing airway compromise.

In addition to the higher incidence of airway compromise seen in patients treated with antibiotics alone, there could be other clinical correlations of importance, particularly for antibiotic therapy failure. It has been well documented by Flynn et al. [8], who reported 21\% cases of therapeutic failure, necessitating reoperation in $8 \%$ of their recruited subjects with odontogenic infections. LOS is another consideration.

Parhiscar and Har-El [11], in their 10-year retrospective review, reported that out of 30 patients with Ludwig's angina, 28 (93\%) were managed with operative drainage with a LOS in the intensive care unit of 2 days and a LOS of 5 days. They concluded that early operative intervention is safe, effective, and is associated with shorter patient stay in the intensive care unit and hospital. However, the authors did not report the LOS of the remaining patients that had no surgical decompression. Rasteniene et al. [15] reported a mean LOS of $8.3 \pm 4.9$ days in their retrospective analysis to assess the determinants of length of hospitalization due to acute odontogenic maxillofacial infections. The LOS in the previous study was greater but was closely related to that of the conservative group and far greater than that of the surgical group.

Since the introduction of fiber optic intubation for difficult airways, it is being argued that airway protection could be achieved more reliably without the need for tracheostomy, and that clinicians could become more comfortable observing patients with early stage Ludwig's angina and relying on antibiotics in what is regarded as watchful waiting. However, this argument cannot be generalized as in the event of antibiotics fail-

Effectiveness Treatment in Early Stage Ludwig's Angina ure resulting in airway compromise in situations where fiberoptic intubation is unavailable or failed, management of the disease at this stage becomes risky and challenging which may lead to increased morbidity and mortality. From the host defense standpoint, antibiotic therapy may not be fully reliable in a subset of the population with immune suppression, especially for bacteriostatic antibiotics that only inhibit bacterial proliferation.

Reports comparing different treatment approaches of early stage Ludwig's angina are extremely few in number. Larawin et al. [16] retrospectively reviewed 103 patients with deep neck infections from 1993 to 2005, and reported Ludwig's angina as the most common infection in $37 \%$ patients, and that the main mode of treatment was a combination of surgical drainage and antibiotic therapy. They reported a mortality of $8.7 \%$ but did not report whether those who succumbed to infection were treated with conservative or surgical approach. Furthermore, the stage of the disease that most patients seek attention was also not reported. Wael et al. [17] reported two cases successfully treated with antibiotics alone without surgical drainage and airway control intervention. While one of the cases presented late stage of Ludwig's angina, the other presented with early stage of the condition. However, they did not report a classical description of Ludwig's angina, which always involves bilateral submandibular and sublingual spaces. Although no mortality was recorded in our study, the higher incidence of airway compromise observed is similar to that reported by Iwu [10], on 2 fatal cases following antibiotic therapy alone and good outcome in 5 cases treated with surgical drainage and antibiotic therapy. These findings could be attributed to adequate, thorough and skilfully performed surgical drainage while antibiotic failure probably caused the reported morbidity and mortality.

Despite the retrospective nature and the small sample studied, the findings in this study, to the best of our knowledge, appear to be the first to be reported in the literature. 


\section{Conclusion}

There was a higher incidence of airway compromise in individuals treated with intravenous antibiotic alone than in those treated with surgical decompression and intravenous antibiotics. We recommend that adequate early surgical intervention and intravenous antibiotics should be the treatment of choice in individuals with early stage Ludwig's angina in resource-challenged centers as the risk of airway compromise will outweigh the benefit of watchful waiting in the event of antibiotic failure.

\section{References}

1 Greenberg S, Huang J, Chang RS, Ananda SN: Surgical management of Ludwig's angina. ANZ J Surg 2007;77:540-543.

2 Bross-Soriano D, Arrieta Gómez JR, PradoCalleros H, et al: Management of Ludwig's angina with small neck incisions: 18 years experience. Otolaryngol Head Neck Surg 2004; 130:712-717.

3 Yilmaz S, Adisen MZ, Misirlioglu M, et al: Assessment of third molar impaction pattern and associated clinical symptoms in a central Anatolian Turkish population. Med Princ Pract 2016;25:169175.

4 David PR, Jacob O: Does surgical decompression in Ludwig's angina decrease hospital stay? ANZ J Surg 2011;81:168-171.

5 Potter JK, Herford AS, Ellis E: Tracheotomy versus endotracheal intubation for airway management in deep neck space infection. J Oral Maxillofac Surg 2002;60:349-354; discussion 354-355.
6 Wolfe MM, Davis JW, Parks SN: Is surgical airway necessary for airway management in deep neck infections and Ludwig angina? J Crit Care 2011;26:11-14.

7 Schuman NJ, Owens BM: Ludwig's angina following dental treatment of a five-year-old male patient: report of a case. J Clin Pediatr Dent 1992;16:263-265.

8 Flynn TR, Shanti RM, Hayes C: Severe odontogenic infections, part 2: prospective outcomes study. J Oral Maxillofac Surg 2006;64: 1104-1113.

9 Swift JQ, Gulden WS: Antibiotic therapy managing odontogenic infections. Dent Clin North Am 2002;46:623-633.

10 Iwu CO: Ludwig's angina: report of seven cases and review of current concepts in management. Br J Oral Maxillofac Surg 1990;28:189193.

11 Parhiscar A, Har-El G: Deep neck abscess: a retrospective review of 210 cases. Ann Otol Rhinol Laryngol 2001;110:1051-1054.
12 Candamourty R, Venkatachalam S, Babu MR, et al: Ludwig's angina - an emergency: a case report with literature review. J Nat Sci Biol Med 2012;3:206-208.

13 Kataria G, Saxena A, Bhagat S, et al: Deep neck space infections: a study of 76 cases. Iran J Otorhinolaryngol 2015;27:293-299.

14 Gbolahan OO, Olowooke S, Aboderin A, et al: Ludwig's angina following self-application of an acidic chemical. Ann Ibadan Postgrad Med 2012;10:34-37.

15 Rasteniene R, Aleksejuniene J, Puriene A: Determinants of length of hospitalization due to acute odontogenic maxillofacial infections: a 2009-3013 retrospective analysis. Med Princ Pract 2015;24:129-135.

16 Larawin V, Naipao J, Dubey SP: Head and Neck Space infections. Otolaryngol Head Neck Surg 2006;136:889-893.

17 Wael H, David L, John R: Ludwig's angina - a controversial surgical emergency: how we do it. Int J Otolaryngol 2011;2011:231816. 